\title{
Population structure of short-finned pilot whales in the oceanic archipelago of Madeira based on photo-identification and genetic analyses: implications for conservation
}

\author{
FILIPE ALVES ${ }^{\mathrm{a}, \mathrm{b}, \mathrm{c}, *}$, SOPHIE QUÉROUIL ${ }^{\mathrm{d}}$, ANA DINIS $^{\mathrm{a}, \mathrm{b}, \mathrm{c}}$, CÁTIA NICOLAU $^{\mathrm{a}}$, CLÁUDIA RIBEIRO $^{\mathrm{a}, \mathrm{c}}$, \\ LUÍS FREITAS $^{\mathrm{a}, \mathrm{c}}$, MANFRED KAUFMANN $^{\mathrm{b}, \mathrm{c}}$ and CATERINA FORTUNA ${ }^{\mathrm{e}}$ \\ ${ }^{a}$ Madeira Whale Museum, Caniçal, Madeira, Portugal \\ ${ }^{\mathrm{b}}$ University of Madeira, Centre of Life Sciences, Marine Biology Station of Funchal, Madeira, Portugal \\ ${ }^{\mathrm{c}}$ CIIMAR/CIMAR - Interdisciplinary Centre of Marine and Environmental Research, University of Porto, Porto, Portugal \\ ${ }^{\mathrm{d}}$ Institut des Sciences de l'Evolution de Montpellier, Université Montpellier 2, Montpellier Cedex 5, France \\ ${ }^{\mathrm{e}}$ Italian National Institute for Environmental Protection and Research, Rome, Italy
}

\begin{abstract}
1. Pilot whales Globicephala spp. are known to display a hierarchical social pattern, but longitudinal data to infer population structure of short-finned pilot whales Globicephala macrorhynchus are rare.

2. Using data collected between 2003-2011 in the oceanic archipelago of Madeira, the grouping structure of short-finned pilot whales was studied using photo-identification methods and mtDNA sequences and microsatellite markers to test the hypotheses that (1) there is at least one pelagic and one or more island-associated communities, and (2) groups are made of related individuals, with a matrilineal social structure.

3. Pilot whales demonstrated a large degree of variability in site fidelity, including residents (up to 14-year interval), regular visitors and transients. The social and temporal analyses revealed a well-differentiated society with long-lasting relationships (of years). The genetic analyses suggested that individuals of the three residency patterns may not be genetically isolated, and that small groups are made up of related individuals, suggesting some degree of social philopatry, while large groups are probably temporary associations of smaller groups.

4. It is proposed that the pilot whales encountered in Madeira belong to a single population encompassing several clans, possibly three clans of island-associated whales and others of transients, each containing two to three matrilineal pods, each with a mean of 15 individuals ( $\mathrm{SD}=9$, range: 4-29). We suggest that the clans interact for mating purposes when they meet.

5. For management decisions, it is considered that the island-associated whales should not be regarded as demographically independent populations, but instead as stable social entities to be included in governmental management plans and requiring periodic evaluation of their status. The high proportion of marked individuals and low rate of mark change encourages further research in this species.

Copyright (C) 2013 John Wiley \& Sons, Ltd.
\end{abstract}

Received 27 July 2012; Revised 20 December 2012; Accepted 31 December 2012

KEY WORDS: island; ocean; ecological status; genetics; habitat management; mammals

\section{INTRODUCTION}

Attempts to understand the behavioural ecology and social structure of wild populations require analysis of the social networks of associations and relationships at the inter-individual level. Such analyses can result in the definition of social

*Correspondence to: Filipe Alves, Museu da Baleia da Madeira, 9200-031 Caniçal, Madeira, Portugal. E-mail: filipealves@museudabaleia.org, filalves@rocketmail.com 
entities and influence the definition of management policies. Photo-identification (photo-id), which is based on the repeated identification of individuals, has become an essential technique in providing information on group stability and association patterns in longitudinal studies (Würsig and Würsig, 1977; Würsig and Jefferson, 1990). Examples include the intensively studied resident killer whales (Orcinus orca) where natal pod philopatry has been evidenced in both sexes (Bigg et al., 1990), or the long-finned pilot whales (Globicephala melas) with non-random social systems based on constant companions (Ottensmeyer and Whitehead, 2003; de Stephanis et al., 2008).

In the case of the short-finned pilot whales (Globicephala macrorhynchus), photo-id was described as a feasible technique for studying their social organization (Miyashita et al., 1990; Shane and McSweeney, 1990), and Heimlich-Boran (1993) found support to the hypothesis that this species has a matrilineal hierarchical system. Even though, up to date, and despite this species being distributed worldwide from tropical to warm-temperate waters and considered abundant throughout its range (Olson, 2009), behavioural longitudinal studies on this species using photo-id are scarce; only Heimlich-Boran (1993) and Mahaffy (2012) have analysed large datasets (of hundreds of individuals) over multiple years.

Another technique that has become widely used for the analysis of population structure in free-ranging cetacean species is molecular genetics. It has been revealed to be of great importance in identifying conservation units and estimating gene flow between demes (cf. Hoelzel et al., 2002). Molecular analyses have also been used to obtain information on social and geographic philopatry in several delphinid species, such as bottlenose dolphins (Tursiops aduncus, Wiszniewski et al., 2010), killer whales (Pilot et al., 2010) or striped dolphins (Stenella coeruleoalba, Gaspari et al., 2007). In most toothed whale species, females form stable matrilineal lineages as a result of social philopatry, while males either disperse (e.g. sperm whales, Physeter macrocephalus) or display geographic philopatry (e.g. bottlenose dolphins) or even social philopatry (e.g. long-finned pilot whales and resident populations of killer whales, Amos et al., 1991a, b, 1993a, b; Connor, 2000).

To our best knowledge, inference on the genetic differentiation of short-finned pilot whales is confined to the studies of Wada (1988) and Oremus et al. (2009). While the former found two genetically isolated forms off the Pacific coast of Japan, the latter analysed worldwide population structure, finding strong mtDNA differentiation between oceanic basins and low haplotype and nucleotide diversity compared to other abundant widespread cetaceans. Nevertheless, and contrarily to its related species (see Amos et al., 1991a, 1993a; Fullard et al., 2000), very little information is available on the population structure of short-finned pilot whales either for the Atlantic or for offshore archipelagos.

The pelagic waters of the archipelago of Madeira are amongst the most isolated oceanic habitats of the north Atlantic. Field surveys conducted over the last decade within the frame of several research projects (see acknowledgments) showed that pilot whales are among the four most encountered odontocete species (our unpublished data). However, scientific knowledge on these whales' ecology and population structure in Madeiran waters is lacking. One study using photographically-identified individuals suggested seasonal site fidelity for Bryde's whales (Balaenoptera brydei) (Alves et al., 2010). Knowing if short-finned pilot whales in Madeiran waters belong to a single large oceanic population and thus be regarded as a single conservation unit, or if they are divided into multiple populations, could greatly improve future management decisions. One could expect an absence of population structure and genetic isolation given the wide spread oceanic habitat surrounding the archipelago and the pelagic nature of this species, which is known to undertake large-scale movements (Bernard and Reilly, 1999). Nevertheless, the presence of island-associated whales in Madeira should be regarded as a possibility, based on a preliminary photo-id analysis (Alves et al., 2007) and on the occurrence of resident pods of this species (Heimlich-Boran, 1993; Mahaffy, 2012).

The present study is the first one to use a combination of photo-id and molecular genetics to determine whether individuals associate with kin and to infer the population structure of pilot whales. In the archipelago of Madeira, the grouping structure of short-finned pilot whales was studied using individually recognizable whales, in order to assess site fidelity, residency and association patterns between 2003-2011. Additionally, mtDNA sequences and microsatellite markers were used to estimate inter-individual relatedness within and between groups of whales encountered during 2004 and 2005. We hypothesized that (1) there is at least 
one pelagic and one or more island-associated communities, and (2) groups are made of related individuals, with a matrilineal social structure. Finally, we expected to contribute to the establishment of effective conservation measures as part of a long-term governmental management plan.

\section{METHODS}

\section{Study site}

The study was conducted around the warm-temperate islands of Madeira, Desertas and Porto Santo, archipelago of Madeira (Portugal). These oceanic volcanic islands lie at $670 \mathrm{~km}$ from Morocco, and steep submarine canyons and deep waters (ca. $1500 \mathrm{~m}$ ) are common around them due to a reduced continental shelf (Geldmacher et al., 2000). The study area covered a total of $4818 \mathrm{~km}^{2}$ up to $20 \mathrm{~km}$ offshore around the three islands. However, since data were obtained through different sources, a more intensely surveyed core area of $\approx 900 \mathrm{~km}^{2}$ was defined along the south and east of Madeira Island, up to $15 \mathrm{~km}$ offshore (Figure 1).

\section{Field procedures}

Individual identification photographs were obtained through year-round systematic and non-systematic surveys, as well as from other sources. One hundred and six systematic surveys (with a mean duration of $11 \mathrm{~h} 30 \mathrm{~min}$ ) were carried out in the whole study area following predefined line-transects using the $18 \mathrm{~m}$ research-yacht Ziphius $\left(12 \mathrm{~km} \mathrm{~h}^{-1}\right)$ during 2004 and 2007-2011. Here, time constraints have limited full photographic coverage of some encounters. One hundred and seventy non-systematic surveys (with a mean duration of $6 \mathrm{~h} 16 \mathrm{~min}$ ) were carried out mainly in the core area using the $6.5 \mathrm{~m}$ Rigid Inflatable Boat Roaz $\left(15-25 \mathrm{~km} \mathrm{~h}^{-1}\right)$ between 2004-2011. All groups of short-finned pilot whales seen were approached and attempts to photograph the left- and right-side of all individuals were made, independently of age class and of how distinctive a dorsal fin was.

A mean of three observers searched the area in Beaufort sea state $\leq 3$, and track courses were registered using a GPS. Weather, effort and sighting information (location, initial time, best estimate of group size and composition) were recorded. A group was defined as all individuals within a $250 \mathrm{~m}$ radius of each other and exhibiting similar behaviour (Heimlich-Boran, 1993). An encounter was defined as a sampling event that provided at least one photographic capture.

\section{Photo-id}

Members of the research team took photographs using digital cameras with lenses ranging between

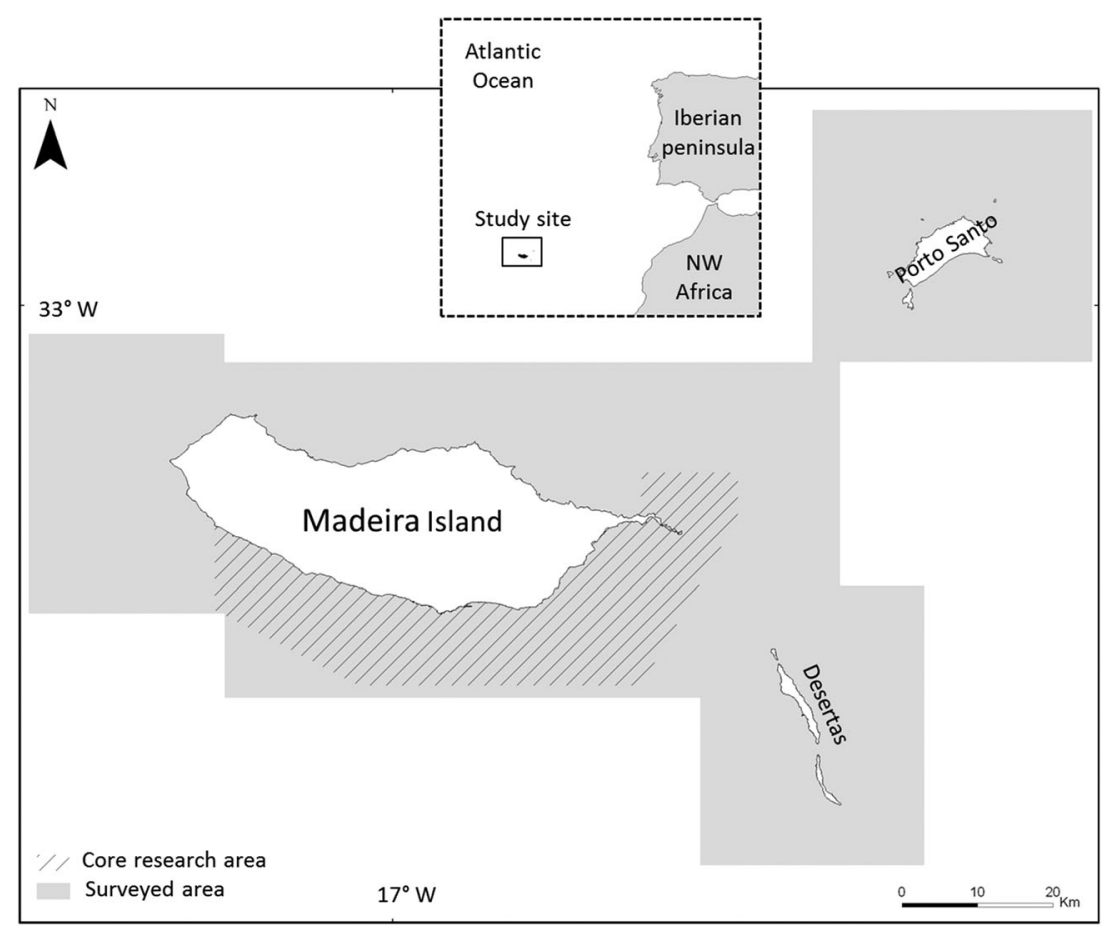

Figure 1. Location of the islands of Madeira, Desertas and Porto Santo, showing the surveyed and the core research areas. 
70-400 mm. Additionally, digital photographs from other photographers taken between 2003-2011 onboard whale-watching boats that operated year-round in the core area were also analysed, and film photographs taken by our team during opportunistic surveys in 1997 and 2001 at south Madeira underwent individual matching examination to help determining long-term site fidelity. A photo-id catalogue was compiled and a dataset of capture histories per encounter was created using the individual identification photographs (Würsig and Jefferson, 1990). A capture was defined as an individual identification within an encounter.

Photo processing consisted of cropping the dorsal fin and the surrounding body area, and adjusting contrast with Adobe Photoshop Elements 3.0. The result was a processed image that highlighted the trailing edge, thus facilitating sorting and matching (Figure 2). Photo matching consisted of comparing processed images based primarily on the number of unique notches on the dorsal fin, which allowed matching left- and right-side photographs. A notch was considered as an indentation in the leading or trailing edge of the dorsal fin, identifiable from both sides (Auger-Méthé and Whitehead, 2007). Other secondary features such as fin shape or scars (Auger-Méthé and Whitehead, 2007) were only used to sort individuals without unique notches, as well as to confirm matches. At the end, all matches were double-checked and all individuals compared in order to avoid false-positives and false-negatives. The photo-id was done by the same person (FA), and the long-term matches were confirmed by a second researcher experienced in photo-id (AD).

A photo quality to the best image of each capture and a distinctiveness category to each catalogued whale were assigned following an independent 1-4 rating (Baird et al., 2009); consisting of poor, fair, good or excellent quality, and non-distinctive, slightly distinctive, distinctive or very distinctive, respectively (Figure 2). The photo quality rating was based on focus, clarity and contrast of the image, and on the angle and size of the dorsal fin relative to the frame (Friday et al., 2000). Captures featuring photo quality 3-4 were defined as high-quality (HQ) images. Non-distinctive individuals were based only on scars or on atypical fin shapes, slightly distinctive individuals had few small notches along the trailing edge, distinctive individuals had multiple notches or at least a big one in the dorsal fin, and very distinctive individuals had similar types of markings but to a greater extent. Individuals with distinctiveness 3-4 were defined as well-marked (WM). Unless otherwise stated, this study used only WM-individuals and HQ-images, thus increasing the certainty of matches. The coverage of the proportion of captures per encounter, calculated as the number of individuals captured divided by the number of individuals in the group, was graded as: low-coverage if this proportion was $<0.3$, medium-coverage if $\geq 0.3$ and $<0.8$, high-coverage if $\geq 0.8$ and $<1$, and full-coverage if $=1$.

Whales were classified in age categories based on the comparison of the relative size of individuals using photographs featuring multiple individuals as well as using field notes, according to descriptions by Yonekura et al. (1980) and Kasuya and Marsh (1984). This study considered immature whales as (calves or juveniles) individuals that had a lighter (grey) colour without a pronounced melon, and that were $<2 / 3$ the length of the adult individual that it was in close association with. Sub-adults were individuals slightly smaller than adults. Due to the difficulty to distinguish between sub-adult males and adult females, the latter were considered only when observed constantly in the presence of an immature.

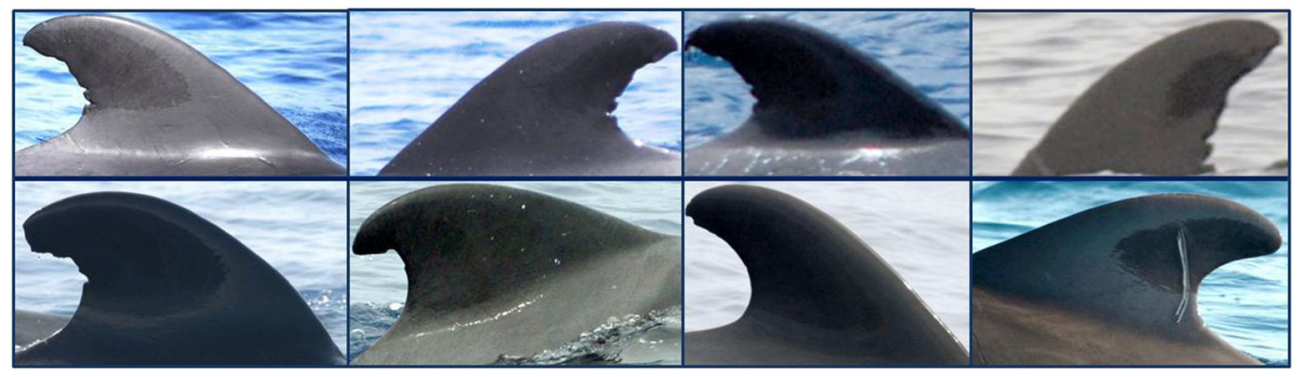

Figure 2. Top (left to right): examples of excellent, good, fair and poor quality images of the very distinctive short-finned pilot whale number 112. Bottom (left to right): examples of very distinctive, distinctive, slightly distinctive and non-distinctive individuals. 


\section{Photographic analysis}

Three residency patterns were considered based on the individual capture histories. Individuals that exhibited multi-year and year-round site fidelity (captured $\geq 5$ times in at least 3 years and 3 seasons, i.e. spring, summer, autumn and winter) were termed residents; individuals captured only once were termed transients; and individuals that fell between these thresholds were considered temporary emigrants/immigrants or regular visitors and thus termed visitors. Exceptions were made in a few cases when individuals were captured only twice within $\leq 8$ days interval, even if in two seasons. These animals were also considered transients since they (1) were probably only passing through, and (2) presented a clear distinct residency pattern from the visitors, that were commonly captured (more than twice) yearly and/or within one or two seasons. Immatures captured only once were assigned the same residency pattern as the respective adults that accompanied them.

The proportion of WM-individuals within groups was estimated using only data from encounters with full-coverage obtained during surveys. A one-way ANOVA and a post-hoc Tukey test were used to check if significant differences existed in the proportion of WM-individuals between groups composed exclusively of residents, of visitors or of transients. Similarly, the proportion of at least slightly distinctive individuals was also estimated to allow comparison with other studies. Estimations included encounters with small (3) and large (33) numbers of individuals, thus not biasing results to sampling only small or large groups, and reducing variance due to not sampling exclusively small groups. To estimate the rate of mark change due to the acquisition of new notches in the dorsal fin over time, the time between the first and last capture for all recaptured individuals was summed and divided by the minimum and maximum number of mark changes that occurred (Aschettino et al., 2011).

Group size was determined at sea using only encounters from surveys, ensuring less biased counts. While the analysis of group size per month used data from encounters of all coverage, the analysis of group size per residency pattern was restricted to encounters with high and full-coverage. Additionally, a group featuring individuals of different residency patterns was termed a mixed group, and in these cases, encounters of all coverage were also used (since a group with a minimum of two individuals of different residency patterns was already considered a mixed group). A two-way ANOVA test was used to check if significant differences in group size existed between months and type of groups (according to residency pattern). To test for a preferential period of occurrence of mixed groups, we used a binomial two-sample proportions test to assess if the proportion of mixed groups (compared to other types of groups, i.e. groups dominated by residents, by visitors or by transients) was significantly different between two predefined periods, i.e. January-June vs. July-December. We used the Shapiro-Wilk and the Levene's tests for the ANOVA assumptions $(\alpha=0.05)$. All the preceding analyses were carried out using the R 2.14.2 statistical package (R Development Core Team, 2012).

\section{Associations}

A social network diagram was created using NetDraw 2.119 (Borgatti, 2002) to illustrate individual association patterns. All encounters were considered, but the ones resulting in a single individual were excluded due to not providing any linking information. Residency pattern was included as an individual attribute.

The simple ratio (Ginsberg and Young, 1992) and the half-weight (Cairns and Schwäger, 1987) association indices were used to represent the strength of the behavioural relationships between dyads, where 0 means two individuals were never recorded associated, and 1 that they were always associated. Considering that the inferences drawn were similar and that the half-weight index is less biased when not all associates are identified (Whitehead, 2008), as it is in the case of this dataset, the results presented here concern the half-weight index.

Hierarchical cluster analysis was used to classify and illustrate relationships between the whales that were captured more often. Only whales captured on $\geq 4$ encounters with high- or full-coverage were used to ensure a more accurate representation. Sampling period as well as associations was defined as individuals grouped within an encounter. Associations were calculated using the average-linkage method due to presenting the highest cophenetic correlation coefficient (CCC) when compared to single-, complete- and Ward'slinkage (not shown), and also due to being less affected by sampling error (Milligan and Cooper, 1987). Knowing that dendrograms impose a hierarchical structured society for a valid 
interpretation (Whitehead, 2008), we considered the CCC (where a value between 0.8 and 1 is a good fit; Bridge, 1993) and tested for preferred/avoided associations using permutation tests (Bejder et al., 1998; Whitehead, 1999). The null hypothesis was that individuals associate with the same probability with all other individuals, given their availability. Observed SD and CV of the pairwise association indices that were significantly larger than those from permuted datasets were taken as evidence that individuals preferred or avoided companions (Whitehead, 1999). To ensure that $P$-values were stable, 1000, 10000 and finally 20000 permutations were generated, and three runs performed using the simple ratio plus three using the half-weight association index. Modularity-G (Newman, 2004) and knot-diagram (Wittemyer et al., 2005; Whitehead, 2008) methods were used for population division. The resulting social entities were defined as 'pods' (Bigg et al., 1990; HeimlichBoran, 1993), and an alphanumeric ID was assigned.

Standardized lagged association rates (SLAR) were used to address temporal patterning in social relationships (Whitehead, 1995). To interpret SLAR we also considered the null rates, which were the values animals would have if associated randomly (see Whitehead (1995) for equations). Moving average was chosen as that which best adjust between precision and smoothing. SLAR were plotted on a $\log \mathrm{x}$-axis time lag scale since time differences between sampling periods ranged over an order of magnitude. We used data from encounters with high- and full-coverage, independently of the number of captures. Sampling period was defined as day, and associations as individuals grouped within an encounter. The precision (SE) was estimated using the temporal jackknife method on each sampling period (Whitehead, 2008). Exponential models representing simulated social structures (Whitehead, 1995) were fitted to the SLAR (Table 1). According to Whitehead (2008), the best fit model was chosen as that which minimized the Quasi Akaike Information Criterion (QAIC). All association analyses were performed with the compiled version of SOCPROG 2.4 (Whitehead, 2009).

\section{DNA analyses}

Thirty-two skin samples were collected in September-November 2004 and in February, September and October 2005 using a biopsy darting system (cf. Mathews et al., 1988). Samples were collected from 14 groups, most were from adult individuals, and the number of samples per group did not exceed $33.3 \%$ of the group size. Details on sampled groups are given in Table 1ESM (electronic supplementary material). Samples were stored in 90\% ethanol and processed at INETI, Lisbon, Portugal. DNA extractions were performed using the DNeasy tissue isolation kit (Qiagen) following the manufacturer's protocol. About $1-2 \mathrm{~mm}^{3}$ of skin were minced and rinsed in dd-water. Digestion by recombinant proteinase $\mathrm{K}$ was extended overnight at $56^{\circ} \mathrm{C}$.

Part of the tRNA-Thr, the tRNA-Pro and the most variable part of the mitochondrial control region were amplified using the primers Dloop- $16^{\mathrm{L}}$ (Hoelzel et al., 1991; $n=24$ short sequences) and H00034 (Rosel et al., 1994) or Dloop-19 ${ }^{\mathrm{H}}$ (Hoelzel et al., 1991; $n=5$ long sequences). PCR reactions were carried out in a $25 \mu \mathrm{l}$ volume using 0.75 units of Taq DNA polymerase (MBI Fermentas) in $\mathrm{KCl}$ buffer with $2 \mathrm{mM} \mathrm{MgCl}_{2}$ and $0.3 \mu \mathrm{M}$ of each primer. The number of cycles was set to 35 and the annealing temperature to $52^{\circ} \mathrm{C}$. PCR products were purified with the GFX PCR DNA purification kit (Amersham Biosciences). Sequencing was done on an ABI-prism capillary sequencer (Applied Biosystems) by Macrogen, Korea. All samples were sequenced with the $16^{\mathrm{L}}$ primer, using an annealing temperature of $55^{\circ} \mathrm{C}$. Five randomly selected samples were also sequenced with the reverse primer, and amplification and sequencing were

Table 1. Fit of social system models to the standardized lagged association rate (SLAR) for all individuals. $\tau$ is time lag in days. CA - casual acquaintances, CC - constant companions. Models ranked by the Quasi Akaike Information Criterion (QAIC); the lowest indicates the best-fitting model. CA is just one interpretation of the SLAR pattern (according to Whitehead, 1995) and not appropriate in this case where we have long-term relationships falling off only after about three years

\begin{tabular}{llr}
\hline Description of model & \multicolumn{1}{c}{ Model formula } & QAmber of parameters \\
\hline CA & $0.092309 e^{(-0.0003214 \cdot \tau)}$ & 2 \\
Two levels of CA & $4.2545 e^{(-3.8546 \cdot \tau)}+0.091674 e^{(-0.0003165 \cdot \tau)}$ & 3973.4 \\
CC + CA & $0.069697+0.19069 e^{(-0.24657 \cdot \tau)}$ & 3975.7 \\
CC & 0.071094 & 4001.9 \\
\hline
\end{tabular}


repeated for two randomly chosen samples, and no mismatches were found. All sequences were carefully checked for errors by visual inspection of peak heights with Chromas Lite 2.01 (freeware available on-line at http://www.technelysium.com. $\mathrm{au} /$ chromas.html). Dubious nucleotides were systematically verified. Alignment was performed visually and no gap was found. Short sequences were of 609 base pairs (bp) and long sequences of 999 bp.

Eight polymorphic dinucleotide microsatellite loci were analysed. PCR reactions were performed in multiplex, using a touch-down protocol with a temperature decrease of $0.1{ }^{\circ} \mathrm{C}$ per cycle over 25 cycles. The initial annealing temperature was set at $52^{\circ} \mathrm{C}$ for Sw10 and Sw19 (Richard et al., 1996), and $56^{\circ} \mathrm{C}$ for EV37 (Valsecchi and Amos, 1996), FCB1 and FCB17 (Buchanan et al., 1996), as well as for Mk6 (Krützen et al., 2001) and $\mathrm{d} 22$ (Shinohara et al., 1997). Locus 468/9 (Amos et al., 1993a) was amplified separately, with a fixed annealing temperature of $45^{\circ} \mathrm{C}$. Fragments were scanned on an ABI 310 capillary sequencer using the size marker ROX350 (Applied Biosystems). Molecular sexing was performed by co-amplification of a short fragment of the male-specific SRY gene (CSY, $157 \mathrm{bp}$; Abe et al., 2001) and a tetranucleotide microsatellite used as a PCR control for positive identification of females (GATA028; Palsbøll et al., 1997), using a touch-down protocol with an initial annealing temperature of $52^{\circ} \mathrm{C}$. Unsuccessful PCR reactions were repeated up to three times. DNA extraction and genotyping were repeated whenever a sample was found not to amplify at three or more loci. Samples that failed this second attempt $(n=2)$ were removed from the data set. Three randomly chosen samples were genotyped twice to verify that results were reproducible.

\section{Identification of replicated samples}

Genotypes were checked for potential errors and replicated individuals using Microsatellite Tools (MsTools; Park, 2001). Allowing for a maximum of two mismatches between samples, one pair of potential replicates with identical genotypes was identified. Extraction and genotyping was repeated for these two samples. Genotype identity was confirmed and one of the two samples was removed from the dataset prior to analyses. There were also two pairs of individuals differing by three mismatches. The mismatching loci were re-analysed and the initial genotypes were confirmed.

\section{Genetic statistical analyses}

As the mtDNA analyses yielded a single haplotype, no statistical analyses were performed on the mtDNA sequences. As for microsatellites, we verified that loci were not in linkage disequilibrium and tested each locus for departure from Hardy-Weinberg frequencies using the exact test implemented in Genepop on the internet (http://genepop.curtin. edu.au/index.html; Genepop 3.3 by Raymond and Rousset, 1995), with default settings. We used a sequential Bonferroni correction to compensate for multiple tests (cf. Rice, 1989). Probability of genotype identity between unrelated and first-order related individuals, allelic diversity, observed $\left(\mathrm{H}_{\mathrm{O}}\right)$ and expected $\left(\mathrm{H}_{\mathrm{E}}\right)$ heterozygosity were calculated with GenAlEx v.6 (Peakall and Smouse, 2006). Despite the small number of samples, an attempt was made to estimate genetic differentiation between resident and transient individuals by means of $\mathrm{F}_{\mathrm{ST}}$ and $\mathrm{R}_{\mathrm{ST}}$ calculated with Arlequin 3.1 (Excoffier et al., 2005). Significance was tested by 10000 permutations. Pairwise relatedness coefficients between individuals were calculated using SPAGeDi 1.2d (Hardy and Vekemans, 2002). The coefficient $\mathrm{r}_{\mathrm{Q} \& \mathrm{G}}$ (Queller and Goodnight, 1989) was selected for being widely used and readily interpretable. For each residency pattern, we calculated the mean degree of relatedness and its variance following Ritland (2000); significant deviation from zero was tested by 10000 permutations, using SPAGeDi $1.2 \mathrm{~d}$ (Hardy and Vekemans, 2002).

We plotted the distribution of pairwise relatedness coefficients within and between groups and searched for potential first order relatives $\left(\mathrm{r}_{\mathrm{Q} \& \mathrm{G}}>0.5\right)$. We tested whether relatedness was higher within than between groups using a permutation procedure, which allowed accounting for the fact that pairwise relatedness coefficients were not independent from one another using Genetix 4.03 (Belkhir et al., 2001) to perform a Mantel test as suggested by Sokal and Rohlf (1995). We searched for a correlation between a matrix of pairwise genetic relatedness $\left(\mathrm{r}_{\mathrm{Q} \& \mathrm{G}}\right)$ and a matrix of group membership encoded as 1 for pairs of individuals sampled in the same group and 0 for pairs of individuals not sampled in the same group. The number of permutations was set to 10000 . We also tested whether there 
was a correlation between mean intra-group relatedness and group size by means of a Spearman's rank test performed with Statistica 6.1. Finally, using all biopsied individuals that had been photo-identified, we searched for a correlation between pairwise relatedness and their half-weight index by means of a Mantel test with 10000 permutations performed with Genetix 4.03 (Belkhir et al., 2001). Half-weight indexes were calculated for all biopsied individuals that had been photo-identified, independently of the number of times they had been encountered. Only HQ-images and groups with high- or full-coverage were included.

\section{RESULTS}

\section{Photo-id}

Over 45000 photographs taken from 405 encounters resulted in 1114 captures and $364 \mathrm{WM}$-individuals based on HQ-images (Table 2). The mean duration of each encounter, calculated as the time between the first and last photograph, was $27 \mathrm{~min}$ $(\mathrm{SD}=23, n=105)$ during surveys, and $14 \mathrm{~min}$ ( $\mathrm{SD}=12, n=300)$ during whale-watching trips; totalling $7014 \mathrm{~min}$ of photo-id. The capture frequency histogram shows different capture probabilities; $71.7 \%$ of the individuals were captured only once and a subset of 10 individuals presented 25 to 33 captures (Figure 3). The discovery curve slightly stabilized throughout the years but not completely by the end of the study, indicating that not all individuals using the area have been captured (Figure 4). Encounters with $100 \%$ of recapture started being common after $2006(\approx 350$ captures). The sampling effort (number of captures) was higher in 2010 and 2011 (Figure 4).

Table 2. Total number of captures and individuals (in bold) and percentages of their respective categories for high-quality images and well-marked individuals

\begin{tabular}{llc}
\hline Captures (total number) & & $\mathbf{1 1 1 4}$ \\
Photo quality & good & $44.5 \%$ \\
& excellent & $55.5 \%$ \\
Individuals (total number) & & $\mathbf{3 6 4}$ \\
Distinctiveness & distinctive & $52.2 \%$ \\
& very distinctive & $47.8 \%$ \\
Age & adults & $95.3 \%$ \\
& sub-adults & $4.1 \%$ \\
& immatures & $0.6 \%$ \\
\hline
\end{tabular}

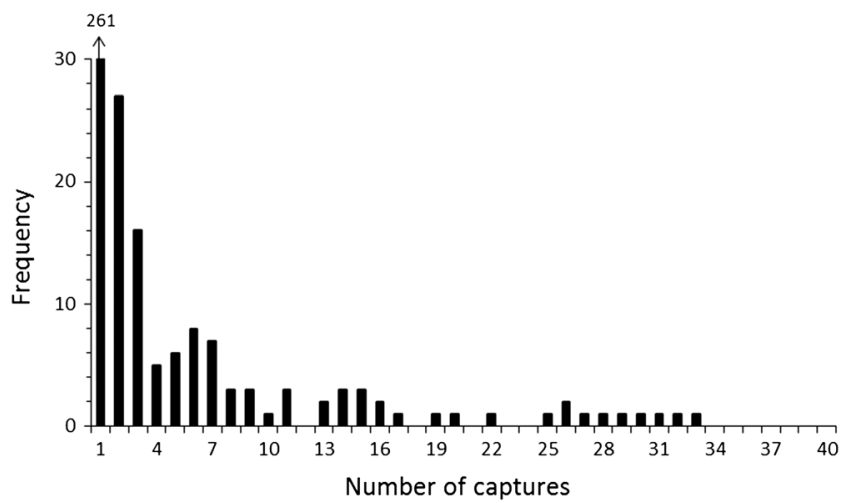

Figure 3. Capture frequency histogram for well-marked individuals based on high-quality images. The y-axis was cut to facilitate visualization of the smaller frequencies.

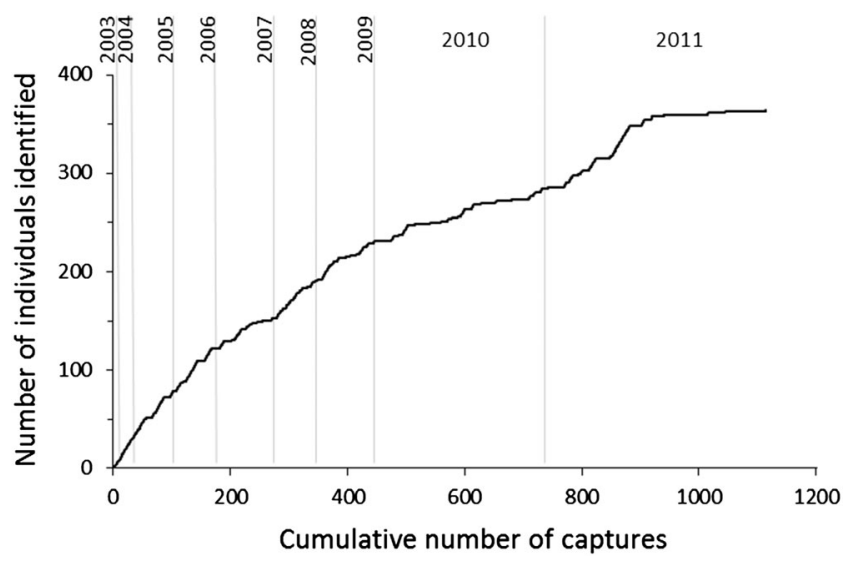

Figure 4. Discovery curve for well-marked individuals based on high-quality images between 2003-2011 (years separated by vertical bars).

Of the 364 individuals, $28.3 \%$ (103 individuals) were recaptured. Of these, $82.5 \%$ (85) were captured in different years. The median inter-annual interval between the first and the last capture for these 85 individuals was 4 years $($ mean $=3.9, \quad \mathrm{SD}=2.2$, range: 1-8) for the study period (2003-2011). For the 103 recaptured whales, individuals captured in 2 years were the most frequent, $>10$ individuals were captured in 3 and 4 years, $<10$ individuals were captured in 5, 6 and 7 years, and one individual was captured in 9 years; indicating site fidelity for a subset of individuals (Figure 5). The matching examination of 19 individuals from opportunistic surveys revealed that (1) one individual captured in October 1997 was an individual that had been captured yearly between 2004-2011, thus presenting a 14-year recapture interval, and (2) one individual captured in January and another one captured in May 2001 were recaptured in January 2011 and June 2010, presenting a 10- and a 9-year recapture interval, respectively. 


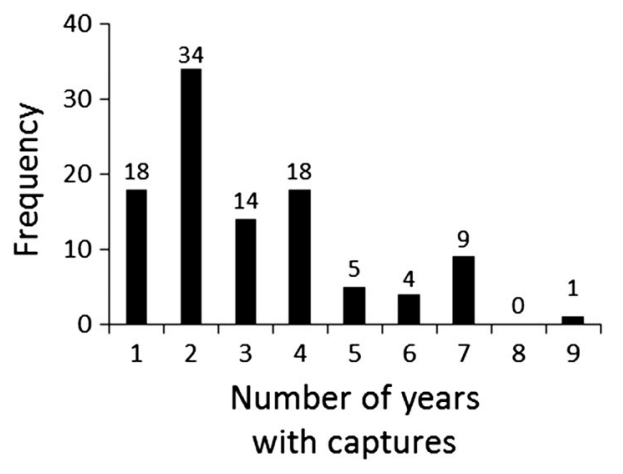

Figure 5. Frequency of the number of years with captures for the 103 well-marked individuals recaptured between 2003-2011. Note that the maximum number of years an individual could be captured was 9 .

\section{Photographic analysis}

Based on 32 groups, a mean proportion of 0.51 individuals $(\mathrm{SD}=0.24$, range: $0.17-1)$ were $\mathrm{WM}$ and $0.78(\mathrm{SD}=0.16$, range: $0.42-1)$ were at least slightly distinctive. Proportions of marked individuals within groups composed exclusively of residents, visitors or transients, differed between groups (Table 3). The inference tests showed that the proportions of marked individuals in groups composed exclusively of transients were significantly higher than those from groups composed exclusively of residents, when either considering WM or slightly distinctive individuals. Twelve groups including individuals of different residency patterns (mixed groups) were excluded (Table 3).

Of the 103 WM-individuals with recaptures, $29(28.2 \%)$ incurred new notches in the dorsal fin. Of these, 17 underwent multiple mark changes. Mark changes were recorded on 43 occasions, for a total of 52 new notches. Considering that multiple mark changes between recaptures could have occurred on either a single or multiple occasions, the actual number of mark change events was somewhere between 42 and 53. The cumulative time between the first and last capture for all individuals captured more than once was 125737 days (343.5 years), thus a new mark event was calculated to occur every $6.6-8.0$ years (mean $=7.3$ years).

Pilot whales were captured in every calendar month. The mean group size was 18 individuals ( median $=15, \mathrm{SD}=12$, range: $2-60, n=105)$. Larger groups were recorded between May-October and were composed of individuals of different residency patterns (Figure 6A-B), however, the two-way ANOVA test revealed no significant differences in group size between months $(P=0.58)$, between type of groups $(P=0.09)$, or due to the interaction of both factors $(P=0.84)$. Groups dominated by resident individuals were naturally recorded year-round. Groups dominated by transients were also recorded year-round (although masked in the second semester by being recorded in mixed groups). Finally, groups dominated by visitors, as well as mixed groups, were proportionally more frequent between August-December (Figure 7). The two-sample proportions test showed that the proportion of mixed groups (compared to other types of groups) was significantly higher $(P<0.001)$ for the period July-December than for January-June. Despite the non-inclusion of the effort analysis in Figure 7 , the probability of encountering mixed groups or another type of groups was the same within each month. The different number of encounters used in each month does not reflect seasonal abundances. A spatio-temporal analysis taking effort into consideration is in preparation and will be published elsewhere. A closer examination of capture histories revealed that mixed groups included all types of possible associations between individuals of different residency patterns.

Table 3. Mean proportions ( $\pm \mathrm{SD}$, range) of well-marked and of at least slightly distinctive individuals from groups composed exclusively of residents (R), of visitors $(\mathrm{V})$, and of transients $(\mathrm{V})$; and $P$-values for the one-way ANOVA and post-hoc Tukey tests $(* 0.01<P<0.05)$. $n-$ number of samples

\begin{tabular}{llr}
\hline & Well-marked individuals & At least slightly distinctive individuals \\
\hline Residents & $0.35( \pm 0.13,0.22-0.50)$ & $0.68( \pm 0.13,0.56-0.83)$ \\
Visitors & $0.49( \pm 0.16,0.33-0.67)$ & $0.79( \pm 0.11,0.67-1)$ \\
Transients & $0.66( \pm 0.22,0.25-1)$ & $0.89( \pm 0.11,0.71-1)$ \\
all groups & $0.51( \pm 0.24,0.16-1)$ & $0.78( \pm 0.16,0.42-1)$ \\
one-way Anova & $P=0.0259^{*}$ & $P=0.0159^{*}$ \\
post-hoc Tukey & $P=0.0222^{*}$ & \\
R - T & $P=0.3983$ & $P=0.0125^{*}$ \\
R - V & $P=0.2096$ & $P=0.2601$ \\
V - T & & $P=0.2229$ \\
\hline
\end{tabular}


A
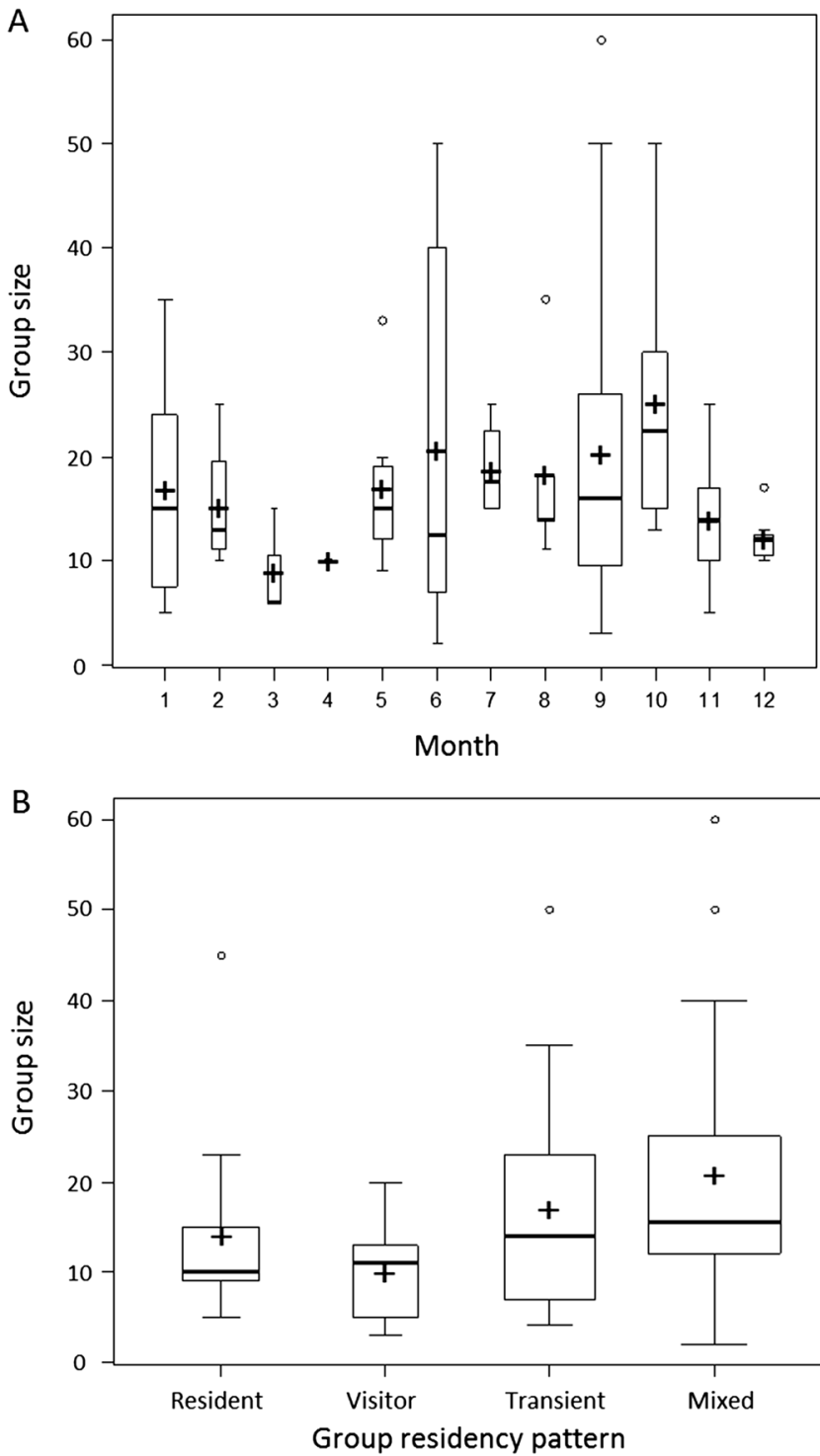

Figure 6. A: boxplots of group size per month, using encounters from surveys $(n=105)$. B: boxplots of group size according to group residency pattern (see definitions in Methods), using encounters where we could apply a category to all (or almost all) individuals of the group $(n=86)$. Middle bold lines indicate median values, + shows the mean, upper and lower lines of boxes encompass the spread of data from the first to the third quartile, and upper and lower horizontal bars show minimum and maximum group sizes unless outliers are present $(O)$, in which case the horizontal bar is defined as the third quartile plus 1.5. The width of the bars is proportional to sample size: $n=3$ in March and $n=35$ in September; $n=10$ for visitors and $n=42$ for mixed. No significant differences were found for any factor (see text).

\section{Associations}

The social network diagram, based on 344 individuals from 246 encounters, shows that 124 individuals $(36 \%)$ form a core social network and the remaining 220 individuals (64\%) form satellite clusters (Figure 8). The diagram comprises 39 $(11.4 \%)$ residents, $72(20.9 \%)$ visitors and 233 $(67.7 \%)$ transients. While the main component includes all the resident individuals, but also

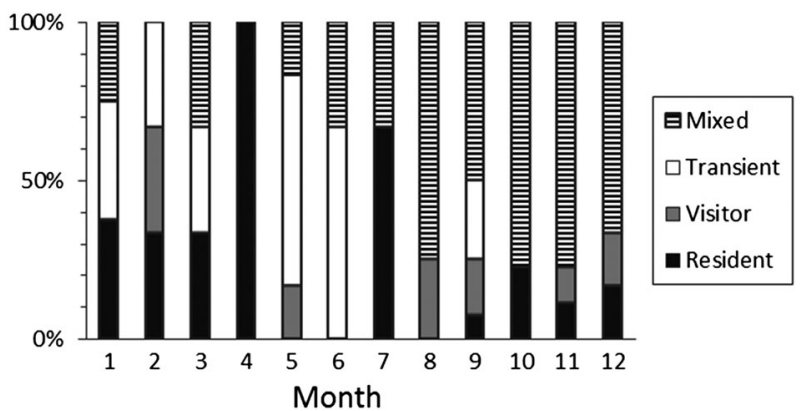

Figure 7. Monthly relative percentage according to group residency pattern (see definitions in Methods). The number of encounters used was $8,3,3,1,6,6,3,4,28,9,9$ and 6 , respectively for January-December. Despite the unequal monthly effort, the probability of capture of each of these groups was equal within each month. The proportion of mixed groups (compared to other types of groups) was significantly higher for the period July-December than for January-June (binomial two-sample proportions test, $P<0.001$ )

visitors and transients, the 46 satellite clusters do not include any resident and were dominated by clusters of transients only (84.8\%). Additionally, the satellite clusters include clusters of visitors only $(6.5 \%)$ as well as clusters with both transients and visitors $(8.7 \%)$.

The SD and CV of the observed pairwise association indices were significantly higher than those from permuted data sets, when using either the simple ratio or the half-weight index $(P<0.001)$, thus rejecting the null hypothesis that individuals associated randomly. The cluster dendrogram (Figure 9, $\mathrm{CCC}=0.96$ ) shows that most of the whales captured on $\geq 4$ encounters were captured with preferred companions, and one pair was always captured together (ID numbers 310 and 493 from pod V3, Table 4). The mean of the half-weight association index per dyad was 0.77. The estimate of social differentiation was $1.87(\mathrm{SE}=0.16)$. A total of 44 individuals from 66 encounters with high- or full-coverage between 2005-2011 were used for this analysis, 33 (75.0\%) residents and $11(25.0 \%)$ visitors.

When assessing population division into social entities, the modularity-G suggests that the best division is with an association index of 0.181 , and the knot-diagram suggests a knot at an association index of 0.471 (Figure 9). The modularity-G peak (0.608) is high, showing that with this division, there is much more total association within pods than would be expected for randomly determined pods. The modularity- $\mathrm{G}$ was the selected method for pod division due to its high maximum value and due to the subjective interpretative nature of the knot-diagram. Therefore, a total of eight pods of variable size and association strength were identified, 


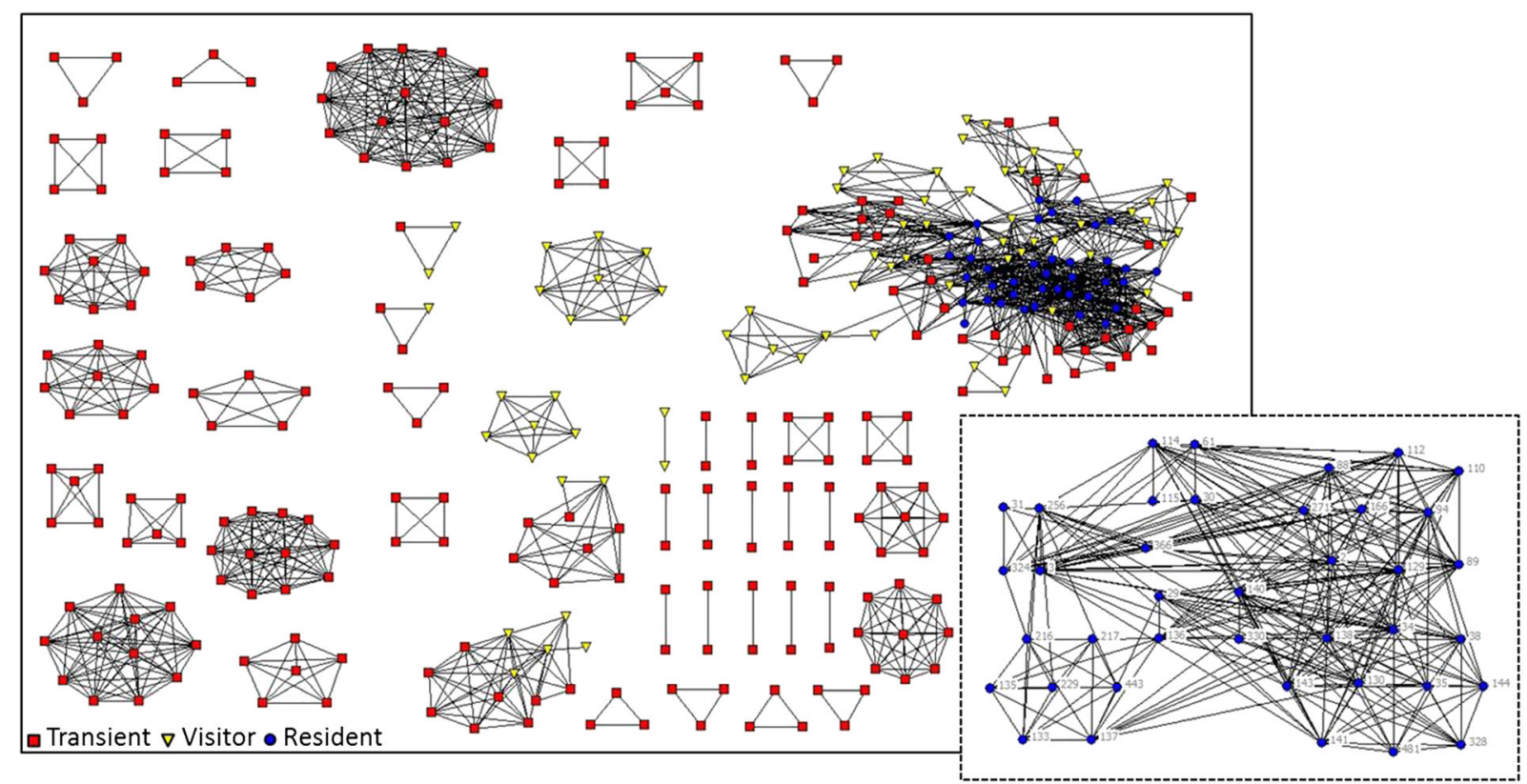

Figure 8. Social network diagram showing associations of 344 well-marked pilot whales around Madeira Islands, using only high-quality images. Nodes correspond to individuals, while lines between nodes represent presence within a group. Symbol shapes and colours indicate individuals residency pattern (see legend inside figure). One hundred and twenty-four individuals $(36 \%)$ are linked to a main cluster, which includes all the residents but also visitors and transients, and the remaining individuals form satellite clusters (mainly composed by transients). Bottom right: detailed view of the resident whales.

five being composed by resident individuals (R1-5) and three by visitors (V1-3). Exceptions occurred in pod R2 where one visitor individual is included, and in pod V3 where one resident individual is included (Figure 9, Table 4). A mean pod size of 15 individuals ( $\mathrm{SD}=9$, range: 4-29) was estimated including marked and non-marked individuals by applying the previously estimated correction factors of the proportion of well-marked individuals to resident and visitor pods (Table 4). A one-way ANOVA revealed no significant differences $(P=0.38)$ between the pod and group mean sizes.

A total of 90 individuals comprising residents, visitors and transients captured during 66 encounters (corresponding to 53 days between 2005-2011) were used to address temporal pattern in social relationships between all individuals in the study area. The SLAR line never reached the null association rate, indicating the absence of random associations for the time scale of $\approx 2000$ days. The line started to decline only after about three years (Figure 10). The best fit model also indicates a social system with long-lasting relationships. Therefore, the fitted model described as 'casual acquaintances' is not appropriate in this case (Table 1). To address temporal pattern in social relationships between individuals of a resident pod the analysis was restricted to the nine individuals from pod R4 (the pod with most captures). The social system model that best fit the curve is described by the model including the constant companion hypothesis over this period (Figure 1ESM).

\section{Genetic analysis}

Among the 29 distinct samples successfully analysed, 12 were females and 17 were males. Females and males of all three residency patterns were recorded (Table 1ESM). All short and all long sequences were identical. The haplotype corresponding to the short sequences perfectly matched the haplotype corresponding to the long sequences (GenBank accession numbers JX144881 and JX144880, respectively). Thus, haplotype diversity was null. Microsatellite allelic diversity ranged between 4 and 11 (Table 5). Average expected heterozygosity ranged between 0.423 and 0.831 . No loci departed from HWE. Loci were not in linkage disequilibrium, except for FCB1 and FCB17 $(P<0.001)$. The probability of genotype identity was $3.8 \mathrm{e}^{10-7}$, and $2.6 \mathrm{e}^{10-3}$ for first order relatives.

Genetic differentiation between individuals identified as resident $(n=13)$ and transient $(n=6)$ was not significant $\left(\mathrm{F}_{\mathrm{ST}}=0.015, P=0.181 ; \mathrm{R}_{\mathrm{ST}}=\right.$ $-0.020 ; P=0.611)$. As for relatedness, mean $\mathrm{r}_{\mathrm{Q} \& \mathrm{G}}$ was $0.004 \quad(\mathrm{SE}=0.238) \quad$ among individuals 


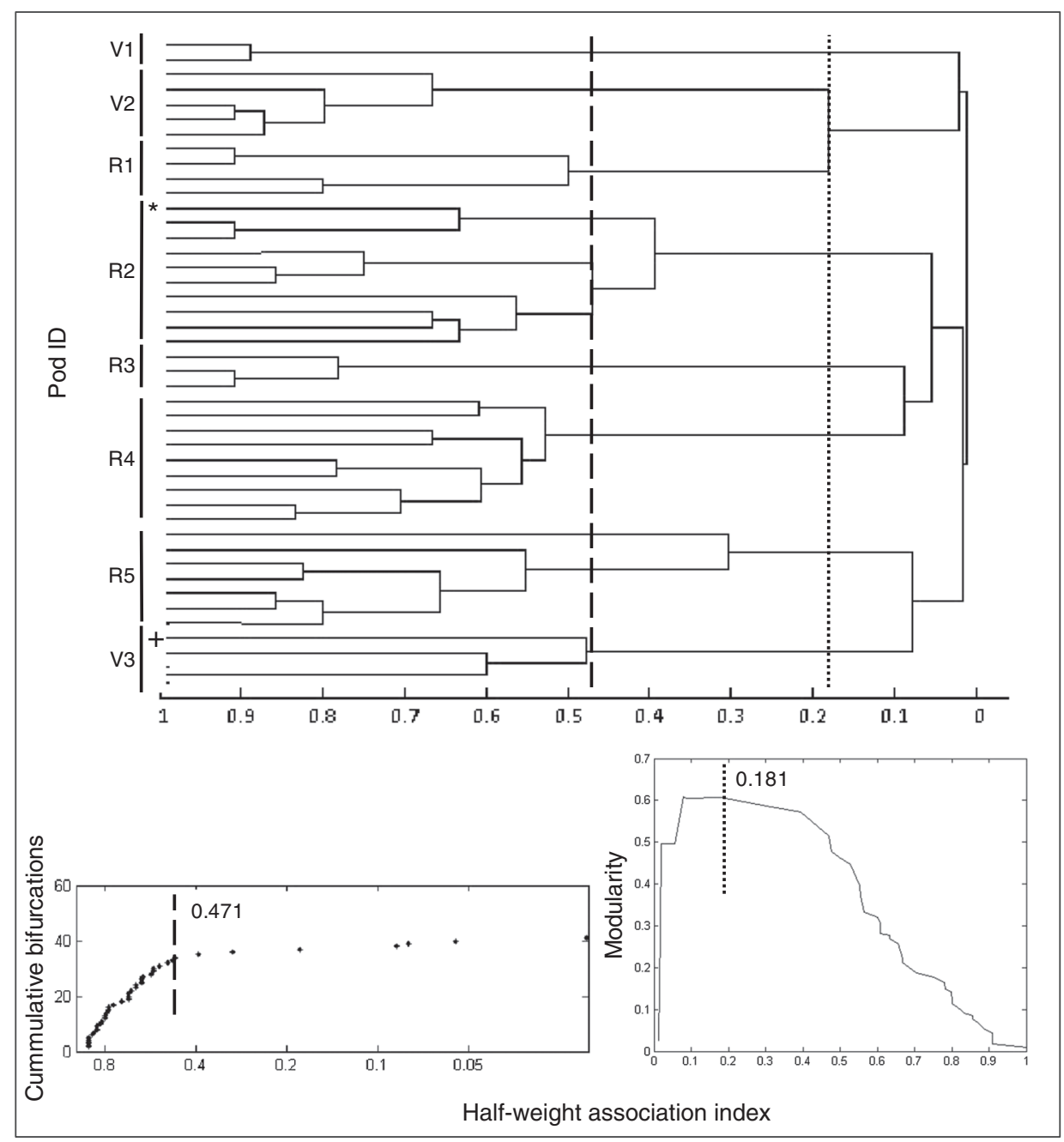

Figure 9. Top: dendrogram produced using average-linkage hierarchical cluster analysis $(\mathrm{CCC}=0.96)$ for 44 well-marked pilot whales based on high-quality images captured on $\geq 4$ encounters with high- or full-coverage. Sampling period as well as associations was defined as individuals grouped within an encounter. Eight pods composed either by residents (R) or by visitors (V) were identified, with exceptions in pods R2 and V3 where one visitor $(*)$ and one resident $(+)$ individuals (as defined in Methods) were included, respectively (see individuals' attributes in Table 4). Bottom left: the knot-diagram suggests a knot at an association index of 0.471 (dashed line). Bottom right: the modularity-G suggests that the best division into pods is with an association index of 0.181 (dotted line).

identified as resident, $-0.054(\mathrm{SE}=0.307)$ among those identified as transient and $-0.037(\mathrm{SE}=0.246)$ in the entire data set. Related individuals $\left(r_{\mathrm{Q} \& G}>0.1\right)$ tended to be over-represented within groups (Figure 11). Noticeably, individuals with $\mathrm{r}_{\mathrm{Q} \& \mathrm{G}}>0.4$ represented $12.1 \%$ of intra-group pairwise comparisons, while between groups their proportion was only $1.9 \%$. In the entire dataset, there were three pairs of individuals with $\mathrm{r}_{\mathrm{Q} \& \mathrm{G}}>0.5$, which could be considered as potential first order relatives. A resident adult female (ID 116) and a resident subadult male that were sampled in the same group had $\mathrm{r}_{\mathrm{Q} \& \mathrm{G}}=0.745$. They shared one allele in common for each microsatellite locus, indicating that they could be mother and offspring. There were also a resident female and a transient male with $r_{\mathrm{Q} \& \mathrm{G}}=0.500$ and a resident male and a male of unknown residency pattern with $\mathrm{r}_{\mathrm{Q} \& \mathrm{G}}=0.574$, which had not been sampled in the same groups. These individuals could not be parent and offspring as they did not share one allele in common at every loci.

Mean $\mathrm{r}_{\mathrm{Q} \& \mathrm{G}}$ within groups (mean $=0.097$, $\mathrm{SE}=0.265$ ) was higher than between groups (mean $=-0.016, \mathrm{SE}=0.237$ ). The Mantel test revealed a significant correlation between genetic relatedness and group membership (Pearson $r=0.161, P=0.003$ ). Mean intra-group relatedness was negatively correlated to group size (Spearman's rank coefficient, $\quad n=8, \quad r=-0.807, \quad P<0.05$; Figure 12). Mean relatedness was high (around 0.3) in groups of up to 30 individuals, and low (below 0) 
Table 4. Attributes and capture histories (black cells mean presence and blank cells mean absence) of the individuals comprising each resident (R) and visitor (V) pod, according to Figure 9 . a - adult, sa - sub-adult, $\mathrm{f}$ - female, $\mathrm{m}$ - male, \# - number. Sex was determined by genetic analysis. * and + relates to exceptions in residency pattern (see Figure 9). Pods size was estimated using the correction factor calculated in this study; 0.49 for visitor pods and 0.35 for resident pods (see Table 3 )

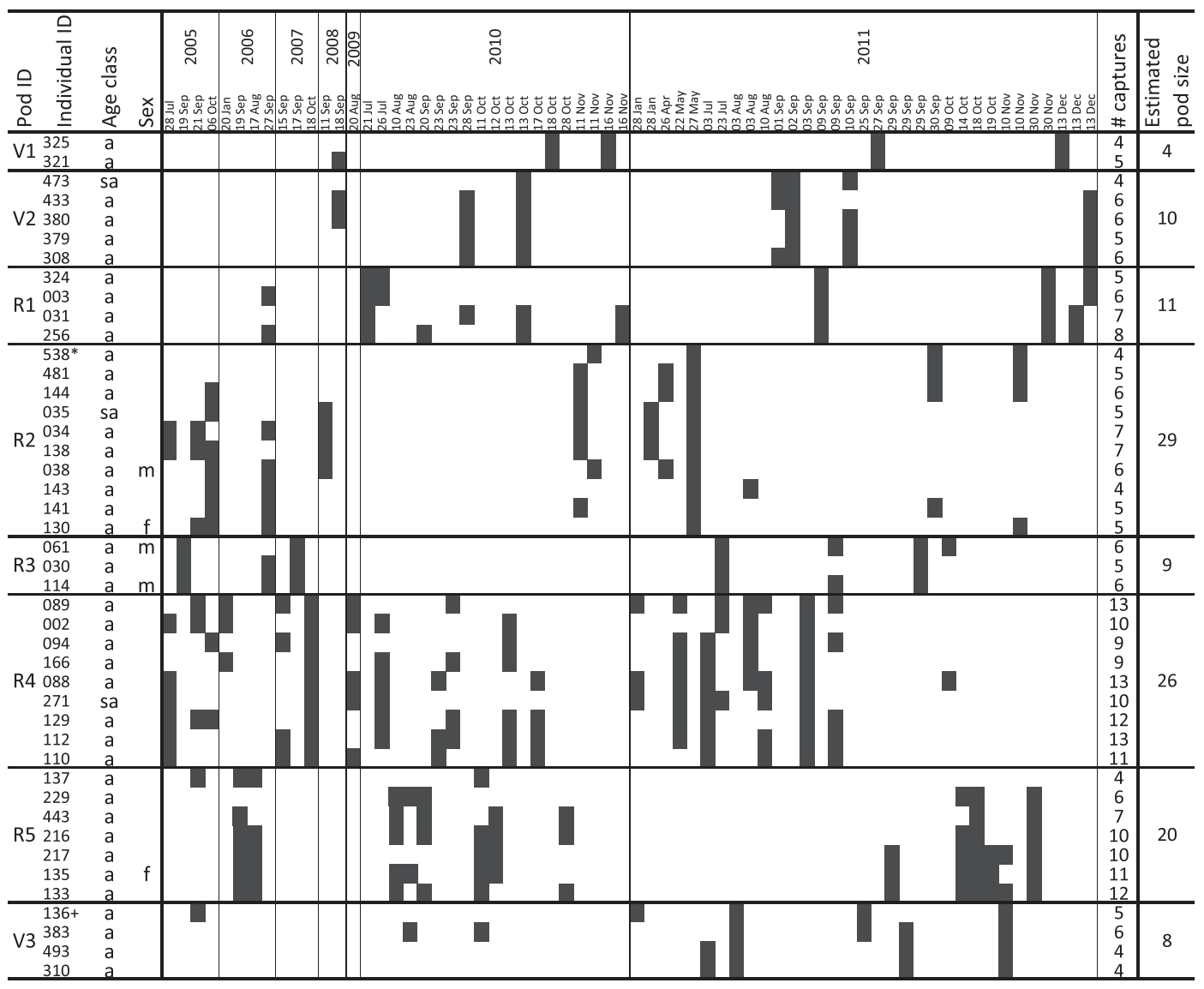

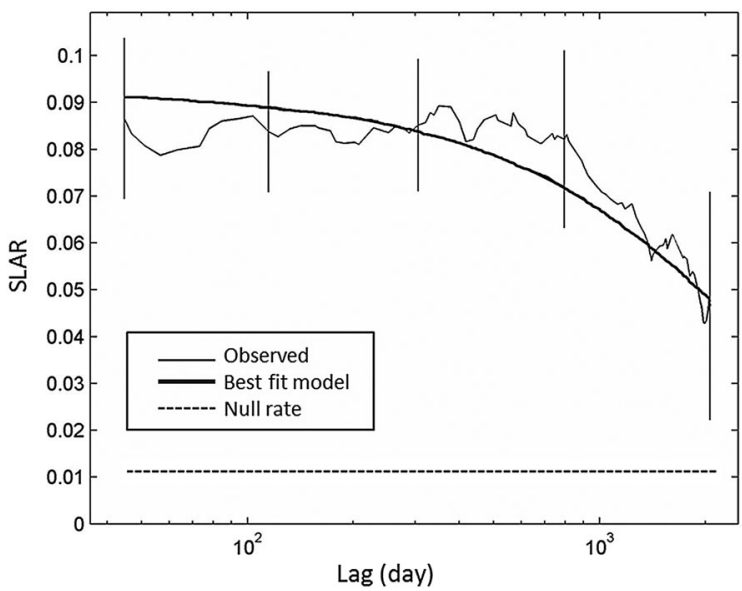

Figure 10. Standardized lagged association rate (SLAR) for 90 well-marked pilot whales captured between 2005-2011. Only highquality images from encounters with high- or full-coverage were used, and a moving average of 8000 associations. Sampling period was defined as day, and associations as individuals grouped within an encounter. Vertical bars indicate SE calculated using the temporal jackknife method on each sampling period. The best fit model indicates a social system with long-lasting relationships. The null association rate represents the theoretical SLAR if individuals associated randomly.
Table 5. Locus-specific microsatellite information: allelic diversity (K), observed $\left(\mathrm{H}_{\mathrm{O}}\right)$ and expected $\left(\mathrm{H}_{\mathrm{E}}\right)$ heterozygosity, and probability of departure from Hardy-Weinberg Equilibrium (HWE, exact test $P$-value)

\begin{tabular}{lrccc}
\hline Locus & $\mathrm{K}$ & $\mathrm{H}_{\mathrm{O}}$ & $\mathrm{H}_{\mathrm{E}}$ & $\mathrm{HWE}(P)$ \\
\hline D22 & 5 & 0.414 & 0.423 & 0.305 \\
EV37 & 7 & 0.552 & 0.687 & 0.077 \\
FCB1 & 11 & 0.828 & 0.831 & 0.445 \\
FCB17 & 8 & 0.793 & 0.725 & 0.567 \\
Mk6 & 4 & 0.655 & 0.565 & 0.691 \\
Sw10 & 4 & 0.552 & 0.458 & 0.237 \\
Sw19 & 8 & 0.621 & 0.698 & 0.330 \\
468/9 & 5 & 0.679 & 0.620 & 0.641 \\
Mean & 6.5 & 0.636 & 0.626 & \\
SD & 2.4 & 0.135 & 0.138 & \\
\hline
\end{tabular}

in groups of 45-50 individuals. In a group of 50 resident individuals where six samples were obtained, average relatedness was low, but two subgroups with a mean relatedness of 0.148 (first two samples) and 0.068 (last four samples) could be defined. In a group of 45 resident individuals where 


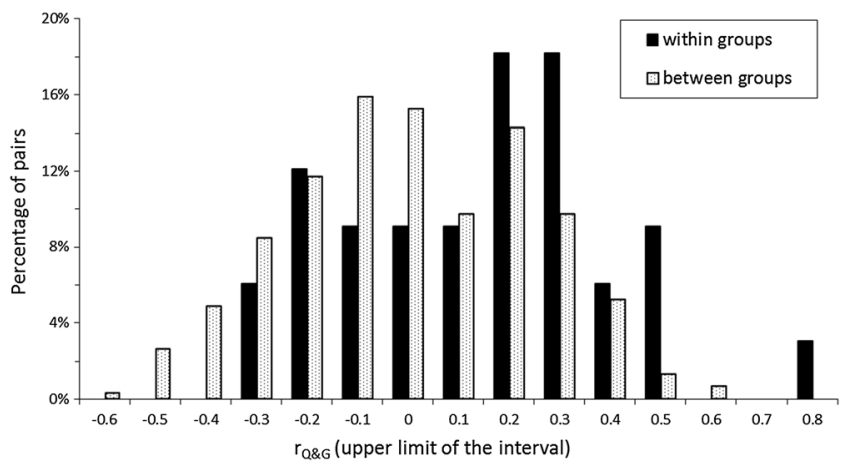

Figure 11. Distribution of pairwise relatedness coefficients within groups $(n=33)$ and between groups $(n=308)$.

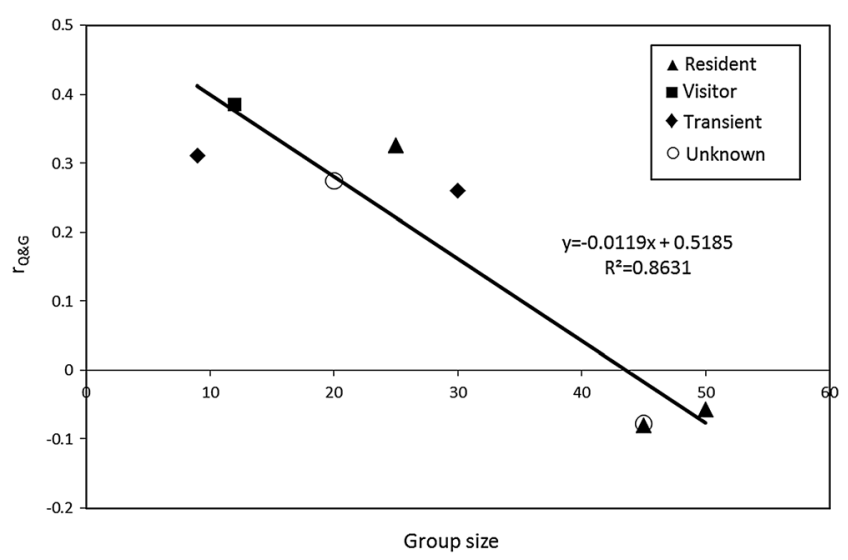

Figure 12. Correlation between mean relatedness within group and group size. Symbols represent group residency pattern.

three samples were obtained, the first sample that was obtained was unrelated to the last two, while the latter two presented a mean relatedness of 0.251 . Finally, there was a significant correlation between pairwise relatedness coefficients and half-weight indexes for the 12 individuals that had been biopsied and photo-identified (Mantel test: Pearson $r=0.380, P=0.002)$.

\section{DISCUSSION}

This study shows that pilot whales demonstrate a large degree of variability in site fidelity, including residents, regular visitors and transients. These differences in patterns of occurrence were not due to a sampling bias since whales from the three types of residency pattern were recorded over the entire course of the study and all were highly distinctive, thus having similar probabilities of being recaptured. The fact that some resident individuals have $>30$ recaptures, and that one resident individual had a 14-year recapture interval, suggests that some short-finned pilot whales exhibit long-term site fidelity in Madeiran waters. Nevertheless, the range of their distribution is unknown, and our findings do not imply that they were always present in the study area. The fact that the visitors regularly visit (and not just pass by) Madeira suggests that these animals come to these waters for either mating and/or feeding. Transients, on the other hand, were captured throughout the entire course of the study and year-round and this suggests that they belong to an open pelagic population that is far from being fully catalogued, and they use the Madeiran waters as a 'passage'. The analysis of the social network diagram shows that these whales associate with visitors and residents during their passage. Independently of the importance of the Madeiran waters for these whales, they constituted about $2 / 3$ of our catalogue. Heimlich-Boran (1993) also reported whales captured only once in the neighbouring archipelago of the Canary Islands. The extent of this 'meta-population' is unknown, and it is likely that some of these whales visit both archipelagos. As suggested by Heimlich-Boran, perhaps they simply return at intervals greater than the length of the study. In fact, in the present study, two whales catalogued as transients had a 10- and a 9-year recapture interval; which may comply with the previous suggestion. Varying patterns of residency have been also commonly documented among cetacean populations (Silva et al., 2008; Baird et al., 2009), however, for pilot whales, only Mahaffy (2012) had described a pattern of habitat usage similar to ours.

The results from mark rate support the occurrence different communities. When comparing the proportion of marked individuals between groups composed exclusively of residents, visitors or transients, groups of transients have more distinctive individuals than groups of residents $(P<0.05)$. Not discarding bias potentially associated with the analysis, individuals of all ages and both sexes had the same capture probability between each residency pattern, thus natural differences can in fact occur. The reason why transients may be more likely to bear dorsal fin notches is beyond the scope of this study. To the best of our knowledge, this is the first study testing the distinctiveness of individuals according to residency pattern, and this question should be addressed in future photo-id studies where groups of different residency patterns co-occur. 
Our results suggest that, despite the existence of three residency patterns in pilot whales around Madeira, resident whales are not isolated from visitors and transients. Mixed groups of individuals with different residency status were frequently observed between July and December, and the social network diagram shows that whales of different residency patterns were photographed together. The genetic analyses did not reveal any differentiation between resident and transient whales, neither for mitochondrial-DNA nor for nuclear-DNA. These analyses are preliminary given the low number of biopsied whales with known residency pattern. Lack of genetic differentiation will have to be confirmed by the analysis of a higher number of individuals of the three residency patterns. It is noteworthy that mitochondrial-DNA haplotype diversity was null. Although short-finned pilot whales are known to have very low mtDNA diversity, which is likely to result from their matrilineal social structure (Whitehead, 1998), this complete lack of diversity was unexpected. It suggests a common ancestry for all biopsied whales, independent of their residency pattern.

The results from group size analysis also support the idea that we are facing one community in the islands, and others that move about and breed when they meet. As observed in various studies performed year-round in other areas, large groups tend to occur at a specific season of the year (e.g. Felleman et al., 1991; Cañadas and Sagarminaga, 2000; de Stephanis et al., 2008). Heimlich-Boran (1993) reported that larger groups of short-finned pilot whales occurred during the summer months in the Canary Islands. His findings are in accordance with ours suggesting that, in the warm-temperate waters of the north-east Atlantic, larger groups of this species occur in the warmer months of the year. The reason for such aggregations could be linked to foraging behaviour, as evidenced for this species and Risso's dolphins (Grampus griseus) off California (Shane, 1995). However, there is not sufficient information about prey availability to infer a similar association for pilot whales in Madeira, nor for the Canary Islands (Heimlich-Boran, 1993). An alternative and non-exclusive hypothesis is that whale aggregations are linked to breeding behaviour. The season of larger group size corresponds to the likely mating period observed in the Canary Islands (Heimlich-Boran, 1993). Similarly, in Madeira, the observation of larger groups coincides with an increase of visitors and a statistically significant higher proportion of mixed groups during the warmer months, making it possible for individuals of different residency patterns to breed. Furthermore, in a matrilineal species, increasing group sizes is believed to occur mainly for reproduction, as suggested for aggregations of long-finned pilot whales (de Stephanis, 2007). Recently, satellite tagging of different clans of pilot whales in the Mediterranean Sea also supported the hypothesis that clans interact for mating purposes when they find each other (Verborgh et al., 2012). Finally, our estimated mean pod size (15, $\mathrm{SD}=9$, range: $4-29$, $n=8$ ) was lower (but not statistically significant) than the mean group size $(18, \mathrm{SD}=12$, range: $2-60$, $n=105$ ). While the low number of pods analysed limits the interpretation, this discrepancy could arise from temporary associations between pods. The means of pod and group sizes obtained in this study are in agreement with observations made in other pilot whale populations (Heimlich-Boran, 1993; Ottensmeyer and Whitehead, 2003; de Stephanis et al., 2008; Mahaffy, 2012).

This study shows that pilot whales in Madeira exhibit a well-differentiated society with long-lasting relationships. The results of the social analysis rejected the null hypothesis that individuals associated randomly and the dendrogram revealed that most of the whales captured on $\geq 4$ encounters were with preferred companions. The temporal analysis also indicated an absence of random associations for the time scale of $\approx 2000$ days (six years). Additionally, despite the SLAR decline, a detailed examination of the capture histories reveal that some resident individuals have been frequently captured together during the six years period considered for the temporal analysis, as corroborated by the SLAR of the pod R4 that fit a constant companion model, with no disassociations over that period. The SLAR decline after a stabilization of approximately two-three years indicates some gradual disassociations over that period, which may indicate a demographic event where individuals are dying or leaving the identified population (Whitehead, 2008). Another explanation is that, when a newborn arrives, the relationship between a mother and a previous calf decreases with time. Considering that the weaning period in this species ranges between 2.5 and 5.5 years (Kasuya and Marsh, 1984), it could have contributed to the decline in the SLAR. The positive correlation between association indexes and genetic 
relatedness coefficients suggested that individuals who associated more tended to be genetically related. This preliminary result would be worth investigating by further analyses.

Genetic relatedness was higher within groups than between groups and highly related individuals tended to be over-represented within groups as compared to between groups. Mean intra-group relatedness was negatively correlated to group size. Although mean relatedness is naturally expected to decline with group size due to a dilution effect, the existence of a correlation implies that small groups are made up of related individuals. Interestingly, genetically related subgroups could be defined within two of the largest groups, which suggest that large groups may be temporary associations of two or more unrelated groups. Similarly, a genetic study on striped dolphins in the Ligurian Sea showed that average relatedness significantly decreased with group size, and concluded that large groups were aggregations of smaller social units (Gaspari et al., 2007). Also in that study, mean relatedness within groups was higher than between groups, especially in females where $r_{Q \& G}$ reached a mean value of 0.221 .

Our results indicate that the pods outlined here represent stable social entities and suggest that short-finned pilot whales may exhibit natal group philopatry, a type of stable matrilineal social structure implying relatedness between members of both sexes within the natal group, as described in killer whales in the coastal eastern North Pacific (Bigg et al., 1990; Barrett-Lennard, 2000). The number of samples available for the genetic analyses was too small to compare relatedness between genders. Mean relatedness coefficients obtained for resident as well as for transient individuals were low, and much lower than in populations of killer whales exhibiting philopatry in both sexes, where mean $\mathrm{r}_{\mathrm{Q} \& \mathrm{G}}$ ranged between 0.102 in transient and 0.305 in resident populations (Pilot et al., 2010). Nonetheless, our study tends to corroborate the hypothesis described by Heimlich-Boran (1993), that the short-finned pilot whale has a matrilineal hierarchical system. The temporal analysis, fitting a constant companion model to a resident pod, also supports the hypothesis that we are facing a matrilineal system. These findings, together with the evidence that long-finned pilot whales also exhibit a matrilineal structure (Amos et al., 1991a, b, 1993a, b; Fullard, 2000) support the idea that Globicephala spp. follow this social pattern.
The final goal of this study is to discuss the implications of our findings for the long-term conservation of this species and the possible management measures that could be implemented. If we had found several populations, or at least one of island-associated/residents and other(s) of oceanic/transients, those would require a high level of concern, with intensive monitoring and possible severe conservation measures, given that population differentiation would prevent gene flow and not enable the island-associated/residents to recover from dramatic events. Instead, the results suggest potential gene flow between different types of communities, which would prevent genetic divergence of island-associated communities. Therefore, there might be a single population in the warm-temperate oceanic waters of the north-east Atlantic. From a conservation standpoint, this 'meta-population' can be regarded as a single management unit, whose preservation can be of extreme importance as it may act as a pool for resident communities. Similar studies should be conducted in the neighbouring archipelagoes of the Canary Islands and Azores to determine whether there is a need for concerted conservation policies at the scale of the North Atlantic. On the other hand, the presence of island-associated whales, whether residents or regular visitors, imply a high risk of exposure to local threats, which can also result in implications for the whole population. Even if we consider that different communities should not be regarded as demographically independent populations, these island-associated whales should be considered as stable social entities in governmental management plans. Therefore, an assessment of the potential threats should be carried out, as well as a periodic evaluation of the status of these social entities. Due to the growing whale-watching industry, proper legislation and/or educational workshops with the operators are also recommended, given that it could minimize the impact over those entities.

To conclude, we would like to raise an often debated but still unsolved question; what is a social entity, or a conservation unit? The social entities observed in the present study were defined as 'pods'. However, the biological significance of pods has been questioned. The term 'pod' that has been used by Bigg et al. (1990) to describe groups of closely related matrilines of killer whales that travel, forage, socialize and rest with each other $\geq 50 \%$ of the time, and are stable over many 
generations, has been later redefined by Ford and Ellis (2002) as transitional groupings that reflect the relatedness of recently diverged matrilines. The clusters that we and Heimlich-Boran (1993) interpreted as meaningful pods are likely the closest equivalent (since it satisfies the criterion of being associated $\geq 50 \%$ of their time) to 'units' in other studies characterizing stable social entities of pilot whales (Ottensmeyer and Whitehead, 2003; de Stephanis et al., 2008; Mahaffy, 2012). Following the suggestion that the social structure of pilot whales is based on clans (i.e. pods which associate regularly; de Stephanis, 2007; de Stephanis et al., 2008), the results from the hierarchical cluster analysis suggest possibly three clans of island-associated whales, one made by pods $\mathrm{V} 1, \mathrm{~V} 2$ and $\mathrm{R} 1$, another by R2, R3 and R4, and a possible third one by R5 and V3.

It is then proposed that the pilot whales encountered in Madeira belong to a single population encompassing several clans, possibly three clans of island-associated whales and others of transients, each containing two to three matrilineal pods, each with a mean of 15 individuals $(\mathrm{SD}=9$, range: 4-29). Given the difficultly in identifying these pods at sea, we suggest that all clans, whether composed of island-associated or of transient whales, should be treated equally as a precautionary approach. Finally, further research in this species is encouraged due to the high proportion of marked individuals and low rate of mark change obtained in our study.

\section{ACKNOWLEDGMENTS}

We wish to thank João Viveiros, Miguel Silva, Hugo Vieira, Filipe Nóbrega, Ana Higueras, Nuno Marques, Marianne Böhm-Beck and Jonatan Svensson for field work assistance; Carlos Silva, Rita Ferreira, Luís Dias, Raquel Marques, Claudia Gomes and Rafael Gomes that greatly contributed with photographs; Adalberto Carvalho for assistance with the map; Raquel Marques for photo-credits (Figure 2 above); Município de Machico, LIFE and FEDER/INTERREG III-B EU programs for funding the data collection throughout the projects CETACEOS MADEIRA (LIFE99 NAT/P/006432), MACETUS (MAC/ 4.2/M10), EMECETUS (05/MAC/4.2/M10) and CETACEOS MADEIRA II (LIFE+ NAT/P/ 000646); Portuguese Foundation for Science and Technology (FCT) for funding SQ's post-doctoral grants (IMAR/FCT-PDOC-006/2001-MoleGen and SFRH/BPD/19680/2004); K. Belkhir for helping with statistical analyses of the genetic data; S. Gaspari for comments on genetics; R. de Stephanis and an anonymous reviewer for valuable suggestions. The experiments comply with the current Portuguese laws. Samples were obtained under credentials Of. 668/04 DAC/DSCN from the Instituto de Conservação da Natureza.

\section{REFERENCES}

Abe H, Goto M, Pastene LA. 2001. Practical use of multiplex fluorescent PCR for Cetacean sex identification. Marine Mammal Science 17: 657-664.

Alves F, Dinis A, Freitas L. 2007. Indications of a regular presence of short-finned pilot whales (Globicephala macrorhynchus) in Madeira island: preliminary analysis. In $21^{\text {st }}$ Conference of the European Cetacean Society, San Sebastian, Spain.

Alves F, Dinis A, Cascão I, Freitas L. 2010. Bryde's whale (Balaenoptera brydei) stable associations and dive profiles: new insights into foraging behavior. Marine Mammal Science 26: 202-212.

Amos B, Barrett J, Dover GA. 1991a. Breeding behaviour of pilot whales revealed by DNA fingerprinting. Heredity 67: 49-55.

Amos B, Barrett J, Dover GA. 1991b. Breeding system and social structure in the Faroese pilot whale as revealed by DNA fingerprinting. Report of the International Whaling Commission (Special Issue) 13: 255-268.

Amos B, Schlötterer C, Tautz D. 1993a. Social structure of pilot whales revealed by analytical DNA profiling. Science 260: 670-672.

Amos B, Bloch D, Desportes G, Majerus TMO, Bancroft DR, Barrett JA, Dover GA. 1993b. A review of the molecular evidence relating to social organisation and breeding system in the long-finned pilot whale. Report of the International Whaling Commission (Special Issue) 14: 209-217.

Aschettino JM, Baird RW, McSweeney DJ, Webster DL, Schorr GS, Huggins JL, Martien KK, Mahaffy SD, West KL. 2011. Population structure of melon-headed whales (Peponocephala electra) in the Hawaiian Archipelago: evidence of multiple populations based on photo-identification. Marine Mammal Science 28: 666-689.

Auger-Méthé M, Whitehead H. 2007. The use of natural markings in studies of long-finned pilot whale (Globicephala melas). Marine Mammal Science 23: 77-93.

Baird RW, Gorgone AM, McSweeney DJ, Ligon AD, Deakos MH, Webster DL, Schorr GS, Martien KK, Salden DR, Mahaffy SD. 2009. Population structure of island associated dolphins: Evidence from photo-identification of common bottlenose dolphins (Tursiops truncatus) in the main Hawaiian Islands. Marine Mammal Science 25: 251-274.

Barrett-Lennard LG. 2000. Population structure and mating patterns of killer whales, Orcinus orca, as revealed by DNA analysis. PhD thesis, University of British Columbia, Vancouver.

Bejder L, Fletcher D, Bräger S. 1998. A method for testing association patterns of social animals. Animal Behaviour 56: 719-725.

Belkhir K, Borsa P, Chikhi L, Raufaste N, Bonhomme F. 2001. Genetix, a Windows software for population Genetics. 
Laboratoire Génome, Populations, Interactions, CNRS UPR 9060, Université de Montpellier II, Montpellier, France.

Bernard HJ, Reilly B. 1999. Pilot whales - Globicephala Lesson, 1828. In Handbook of Marine Mammals Vol. 6: The second book of dolphins and porpoises, Ridgway SH, Harrison SR (eds). Academic Press: San Diego, CA; 245-280.

Bigg MA, Olesiuk PF, Ellis GM, Ford JKB, Balcomb KC. 1990. Social organization and genealogy of resident killer whales (Orcinus orca) in the coastal waters of British Columbia and Washington State. Report of the International Whaling Commission (Special Issue) 12: 383-405.

Borgatti SP. 2002. NetDraw: Graph Visualization Software. Harvard, Analytic Technologies.

Bridge PD. 1993. Classification. In Biological Data Analysis: A Practical Approach, Fry JC (ed.). Oxford University Press: New York; 219-242.

Buchanan F, Friesen M, Littlejohn R, Clayton J. 1996. Microsatellites from the beluga whale (Delphinapterus leucas). Molecular Ecology 5: 571-575.

Cairns JS, Schwäger SJ. 1987. A comparison of association indices. Animal Behaviour 35: 1454-1469.

Cañadas A, Sagarminaga R. 2000. The northeastern Alboran Sea, an important breeding and feeding ground for the long finned pilot whale (Globicephala melas) in the Mediterranean Sea. Marine Mammal Science 16: 513-529.

Connor RC. 2000. Group living in whales and dolphins. In Cetacean societies: Field studies of dolphins and whales, Mann J, Connor RC, Tyack PL, Whitehead H (eds). The University of Chicago Press: Chicago; 199-218.

de Stephanis R. 2007. Estrategias de alimentación de los diferentes grupos de Calderón común (Globicephala melas) en el Estrecho de Gibraltar. Implicaciones para su conservación. $\mathrm{PhD}$ thesis, Universidad de Cádiz, Spain.

de Stephanis R, Verborgh P, Pérez S, Esteban R, Minvielle-Sebastia L, Guinet C. 2008. Long-term social structure of long-finned pilot whales (Globicephala melas) in the Strait of Gibraltar. Acta Ethologica 11: 81-94.

Excoffier L, Laval G, Schneider S. 2005. Arlequin ver. 3.0: An integrated software package for population genetics data analysis. Evolutionary Bioinformatics Online 1: 47-50.

Felleman FL, Heimlich-Boran JR, Osborne RW. 1991. The feeding ecology of killer whales (Orcinus orca) in the Pacific Northwest. In Dolphin Societies: discoveries and puzzles, Pryor K, Norris KS (eds). University of California Press: Berkley; 113-147.

Ford JKB, Ellis GM. 2002. Reassessing the social organization of resident killer whales in British Columbia. In Fourth International Orca Symposium and Workshop. CEBC-CNRS: France; 72-74.

Friday N, Smith TD, Stevick PT, Allenin J. 2000. Measurement of photographic quality and individual distinctiveness for the photographic identification of humpback whales, Megaptera novaeangliae. Marine Mammal Science 16: 355-374.

Fullard K. 2000. Microsatellite analysis of long-finned pilot whales. PhD thesis, Cambridge University, England.

Fullard KJ, Early G, Heide-Jørgensen MP, Bloch D, Rosing-Asvid A, Amos W. 2000. Population structure of long-finned pilot whales in the North Atlantic: a correlation with sea surface temperature? Molecular Ecology 9: 949-958.

Gaspari S, Azzellino A, Airoldi S, Hoelzel AR. 2007. Social kin associations and genetic structuring of striped dolphin populations (Stenella coeruleoalba) in the Mediterranean Sea. Molecular Ecology 16: 2922-2933.

Geldmacher J, Van Den Bogaard P, Hoernle K, Schmincke HU. 2000. The 40Ar/39Ar age dating of the Madeira Archipelago and hotspot track (eastern North Atlantic). Geochemistry, Geophysics, Geosystems 1: 1999GC000018.
Ginsberg JR, Young TP. 1992. Measuring association between individuals or groups in behavioural studies. Animal Behaviour 44: 377-379.

Hardy OJ, Vekemans X. 2002. SPAGeDI: a versatile computer program to analyse spatial genetic structure at the individual or population levels. Molecular Ecology Notes 2: 618-620.

Heimlich-Boran JR. 1993. Social organization of the short-finned pilot whale, Globicephala macrorhynchus, with special reference to the comparative social ecology of delphinids. $\mathrm{PhD}$ thesis, Cambridge University, England.

Hoelzel AR, Hancock JM, Dover GA. 1991. Evolution of the cetacean mitochondrial D-loop region. Molecular Biology and Evolution 8: 475-493.

Hoelzel AR, Goldsworthy SD, Fleischer RC. 2002. Population genetic structure. In Marine mammal biology: an evolutionary approach, Hoelzel AR (ed.). Blackwell Science Ltd: Oxford; 325-352.

Kasuya T, Marsh H. 1984. Life history and reproductive biology of the short-finned pilot whale, Globicephala macrorhynchus, off the Pacific coast of Japan. Report of the International Whaling Commission (Special Issue) 6: 259-310.

Krützen M, Valsecchi E, Connor RC, Sherwin WB. 2001. Characterization of microsatellite loci in Tursiops aduncus. Molecular Ecology Notes 1: 170-172.

Mahaffy SD. 2012. Site fidelity, associations and long-term bonds of short-finned pilot whales off the island of Hawai'i. Master thesis, Portland State University, USA.

Mathews EA, Keller S, Weiner DB. 1988. A method to collect and process skin biopsies for cell culture from the free-ranging gray whales (Eschrichtius robustus). Marine Mammal Science 4: 1-12.

Milligan GW, Cooper MC. 1987. Methodology review: clustering methods. Applied Psychological Measurement 11: $329-354$.

Miyashita T, Kasuya T, Mori K. 1990. An examination of the feasibility of using photo-identification techniques for a short-finned pilot whale stock off Japan. Report of the International Whaling Commission (Special Issue) 12: $425-428$.

Newman MEJ. 2004. Analysis of weighted networks. Physical Review E 70: 056131.

Olson P. 2009. Pilot whales Globicephala melas and G. macrorhynchus. In Encyclopedia of marine mammals 2nd Ed, Perrin WF, Würsig B, Thewissen JGM (eds). Academic Press: Amsterdam; 847-852.

Oremus M, Gales R, Dalebout ML, Funahashi N, Endo T, Kage T, Steel D, Baker SC. 2009. Worldwide mitochondrial DNA diversity and phylogeography of pilot whales (Globicephala spp.). Biological Journal of the Linnean Society 98: 729-744.

Ottensmeyer CA, Whitehead H. 2003. Behavioural evidence for social units in long-finned pilot whales. Canadian Journal of Zoology 81: 1327-1338.

Palsbøll PJ, Bérubé M, Larsen AH, Jorgensen H. 1997. Primers for the amplification of tri- and tetramer microsatellite loci in baleen whales. Molecular Ecology 6: 893-895.

Park SDE. 2001. Trypanotolerance in West African cattle and the population genetic effects of selection. PhD thesis, University of Dublin, Ireland.

Peakall R, Smouse PE. 2006. GenAlEx 6: genetic analysis in Excel. Population genetic software for teaching and research. Molecular Ecology Notes 6: 288-295.

Pilot M, Dahlheim ME, Hoelzel RA. 2010. Social cohesion among kin, gene flow without dispersal and the evolution of population genetic structure in the killer whale (Orcinus orca). Journal of Evolutionary Biology 23: 20-31.

Queller DC, Goodnight KF. 1989. Estimating relatedness using genetic markers. Evolution 43: 258-275. 
R Development Core Team. 2012. R: A language and environment for statistical computing. $\mathrm{R}$ Foundation for Statistical Computing: Vienna, Austria. ISBN 3-900051-07-0, URL http://www.R-project.org/.

Raymond M, Rousset F. 1995. Genepop (version 1.2), population genetics software for exact tests and ecumenicism. Journal of Heredity 86: 248-249.

Rice WR. 1989. Analysing tables of statistical tests. Evolution 43: 223-225.

Richard KR, Whitehead H, Wright JM. 1996. Polymorphic microsatellites from sperm whales and their use in the genetic identification of individuals from naturally sloughed pieces of skin. Molecular Ecology 5: 313-315.

Ritland K. 2000. Marker-inferred relatedness as a tool for detecting heritability in nature. Molecular Ecology 9: $1195-1204$.

Rosel PE, Dizon AE, Heyning JE. 1994. Genetic analysis of sympatric morphotypes of common dolphins (genus Delphinus). Marine Biology 119: 159-167.

Shane SH. 1995. Relationship between pilot whales and Risso's dolphins at Santa Catalina Island, California, USA. Marine Ecology Progress Series 123: 5-11.

Shane SH, McSweeney D. 1990. Using photo-identification to study pilot whale social organization. Report of the International Whaling Commission (Special Issue) 12: 259-263.

Shinohara M, Domingo-Roura X, Takenaka O. 1997. Microsatellites in the bottlenose dolphin Tursiops truncatus. Molecular Ecology 6: 695-696.

Silva MA, Prieto R, Magalhães S, Seabra MI, Santos RS, Hammond PS. 2008. Ranging patterns of bottlenose dolphins living in oceanic waters: implications for population structure. Marine Biology 156: 179-192.

Sokal RR, Rohlf FJ. 1995. Randomization tests. In Biometry (3rd ed.), Sokal RR, Rohlf FJ (eds). WH Freeman: New York: 818-819.

Valsecchi E, Amos W. 1996. Microsatellite markers for the study of cetacean populations. Molecular Ecology 5: $151-156$
Verborgh P, de Stephanis R, García P, Murcia JL, Andrews R, Cañadas A, Gauffier P, Giménez J, Esteban R. 2012. The territorial long-finned pilot whales of the Alboran Sea. In $26^{\text {th }}$ Conference of the European Cetacean Society, Galway, Ireland.

Wada S. 1988. Genetic differentiation between two forms of short-finned pilot whales off the Pacific coast of Japan. Scientific Reports of the Whales Research Institute 39: 91-101

Whitehead H. 1995. Investigating structure and temporal scale in social organizations using identified individuals. Behavior Ecology 6: 199-208.

Whitehead H. 1998. Cultural selection and genetic diversity in matrilineal whales. Science 282: 1708-1711.

Whitehead H. 1999. Testing association patterns of social animals. Animal Behaviour 57: F26-F29.

Whitehead H. 2008. Analyzing animal societies: quantitative methods for vertebrate social analysis. University of Chicago Press: Chicago.

Whitehead H. 2009. SOCPROG programs: analyzing animal social structures. Behavioral Ecology and Sociobiology 63: 765-778.

Wiszniewski J, Beheregaray LB, Allen SJ, Möller LM. 2010. Environmental and social influences on the genetic structure of bottlenose dolphins (Tursiops aduncus) in Southeastern Australia. Conservation Genetics 11: 1405-1419.

Wittemyer G, Douglas-Hamilton I, Getz WM. 2005. The socio-ecology of elephants: analysis of the processes creating multi-tiered social structures. Animal Behaviour 69: $1357-1371$.

Würsig B, Jefferson TA. 1990. Methods of photo-identification for small cetaceans. Report of the International Whaling Commission (Special Issue) 12: 42-43.

Würsig B, Würsig M. 1977. The photographic determination of group size, composition, and stability of coastal porpoises (Tursiops truncatus). Science 198: 755-756.

Yonekura M, Matsui S, Kasuya T. 1980. On the external characters of Globicephala macrorhynchus off Taiji, Pacific coast of Japan. Scientific Reports of the Whales Research Institute 32: 67-95. 